\title{
Effective and Reliable Speed Control of Permanent Magnet DC (PMDC) Motor under Variable Loads
}

\author{
Murat Tuna*, Can Bülent Fidan**, Süreyya Kocabey ${ }^{\dagger}$ and Sertaç Görgülü***
}

\begin{abstract}
This paper presents the effective and reliable speed control of PMDC motors under variable loads and reference speeds. As is known DC motors are more preferred in industrial practices. This is that, the PMDC motors don't require brush and commutator care and to increase in torque per motor depending on developments in power electronics. In this study, proportional-integral controller (PI) and fuzzy logic controller (FL) have been designed for speed control of PMDC motor. In the design of these controllers, characteristics such as minimum overrun time, response time to the load, settling time and ideal rise time have been taken into consideration for better stability performance. In this design, the best system response was searched by examining the effect of different defuzzification methods onto the fuzzy logic system response. In conclusion, it has been seen that FL controller has a better performance for variable speed-load control of PMDC motor compared to PI controller.
\end{abstract}

Keywords: Electrical vehicle, Fuzzy Logic control (FLC), PI controller, PMDC motor, Speed control

\section{Introduction}

DC motors which are one of the machines that transform electric energy into mechanic energy and driver control systems are used in many fields of industry. Especially, the PMDC motors without brushless find more usage areas day by day in applications like automotive, space technologies, computer, medical electronics, military, robotics, electrical vehicles and products because of their such superiorities as high moment/current and moment/inactivity rate, strong structure, high performance, permanent control features and reliability [1-4].

In recent years, the methods of DC motor speed controls vary. These are expert systems realized as nonlinear adaptive variable structure based on fuzzy logic based, artificial neural networks, slippery mode control, genetic algorithm and conventional control strategies that have PID, PI and PD algorithms [5-7].

PI controllers have the most common usage area due to the fact that they have simple structures and easily managed control algorithm. Control parameters are arranged usually manually or with the Ziegler-Nichols frequency method. Although successful results were obtained from both methods, a satisfactory system response is obtained with a long time and try. In the PI control of the PMDC motors is encountered with two major problems. The first of them;

$\dagger$ Corresponding Author: Dept. of Energy Systems Engineering, Kırklareli University, Turkey. (sureyyakocabey@klu.edu.tr)

* Dept. of Electrical and Energy, Kirklareli University, Turkey. (murat.tuna@klu.edu.tr)

** Dept. of Mechatronic Engineering, Karabük University, Turkey (cbfidan@karabuk.edu.tr)

*** Dept. of Energy Systems Engineering, Mehmet Akif University, Turkey. (sgorgulu@mehmetakif.edu.tr)

Received: January 24, 2015; Accepted: June 1, 2015 change of motor parameters depending on the operating conditions with time and secondly; this is because there is noise in the system cycle. Giving the best system response to reference speed is expected from speed controllers of PMDC motors under variable loads in accordance with such criteria as less overshoot $\left(M_{p}\right)<10 \%$, no steady state error $\left(e_{s s}\right)<1 \%$, minimum settling time $\left(t_{s}\right)<2 \mathrm{~s}$ and minimum rising time $\left(t_{r}\right)<1 \mathrm{~s}[8]$.

However, the conventional PI controller doesn't give the expected response in variable loads and reference speeds, and can't meet the criteria required above. For this reason, an intelligent controller must be used to obtain the best system response to applied reference speeds under variable loads. Intelligent Control theory (Zadeh, 1965) have been proposed to overcome the uncertainty of traditional methods in the analysis and control of complex and nonlinear systems. This intelligent control theory is called Fuzzy Logic Control. One of the most significant advantages of fuzzy logic control is to control the nonlinear complex systems successfully using control engineering information or expert experiences without having any mathematical model [9, 10]. The fuzzy logic control, considering the experiences of the operator on system, performs the control process with linguistic expressions, and by using the mechanisms of rule base, fuzzification and defuzzification. In order to determine the fuzzy rules, the system output response is obtained by analyses in different points $[11,12]$.

In this study, the mathematical model of PMDC motor was simulated in Matlab/Simulink program. PI and FL control methods used for the speed control of PMDC motor in nonlinear speeds and under variable load were compared for better stability performance. Besides, the best system response was searched by examining the effect of different 
defuzzification methods onto the fuzzy logic system response.

\section{Dynamic Model of PMDC Motor}

PMDC motor has many desired qualities in a motor. Some of them are safety, stability, low cost, easy control and the ability to run in low voltage. In addition, the absence of brushes and collectors has substantially eliminated the disadvantage of permanent care. Because of these, DC motors are preferred in many applications [1, 3-4]. The mathematical expression of PMDC motor equivalent circuit showed in Fig. 1 was drawn from the Eqs. (1-5).

$$
\begin{gathered}
V_{a}(t)=R_{a} * i_{a}(t)+L_{a} * \frac{d i_{a}(t)}{d t}+E_{b}(t) \\
E_{b}(t)=K_{b} * \omega_{m}(t) \\
T_{m}(t)=K_{t} * i_{a}(t) \\
K_{t}=K_{b}=k \\
T_{m}(t)=J_{m} * \frac{d \omega_{m}(t)}{d t}+B_{m} * \omega_{m}(t)+T_{L}(t)
\end{gathered}
$$

The differential equation sets above for armature current " $i_{a}$ " and angular velocity " $w_{m}$ " which are the variables of control system can be expressed as in Eq. (6) in the form of state-space.

$\frac{d}{d t}\left[\begin{array}{c}i_{a} \\ \omega_{m}\end{array}\right]=\left[\begin{array}{cc}-\frac{R_{a}}{L_{a}} & -\frac{k}{L_{a}} \\ \frac{k}{J_{m}} & -\frac{B_{m}}{J_{m}}\end{array}\right] *\left[\begin{array}{c}i_{a} \\ \omega_{m}\end{array}\right]+\left[\begin{array}{cc}\frac{1}{L_{a}} & 0 \\ 0 & -\frac{1}{J_{m}}\end{array}\right] *\left[\begin{array}{c}V_{a} \\ T_{L}\end{array}\right](6)$

where;

$V_{a}=$ armature voltage $(V)$

$R_{a}=$ armature resistance $(\Omega)$

$i_{a}=$ armature current $(A)$

$K_{t}=$ torque constant $(\mathrm{Nm} / \mathrm{A})$

$K_{b}=$ back emf constant $(\mathrm{Vs} / \mathrm{rad})$

$J_{m}=$ rotor inertia $\left(\mathrm{kgm}^{2}\right)$

$L_{a}=$ armature inductance $(H)$

$E_{b}=$ back emf $(V)$

$B_{m}=$ viscous friction coefficient $(\mathrm{Nms} / \mathrm{rad})$

$T_{L}=$ load torque $(\mathrm{Nm})$

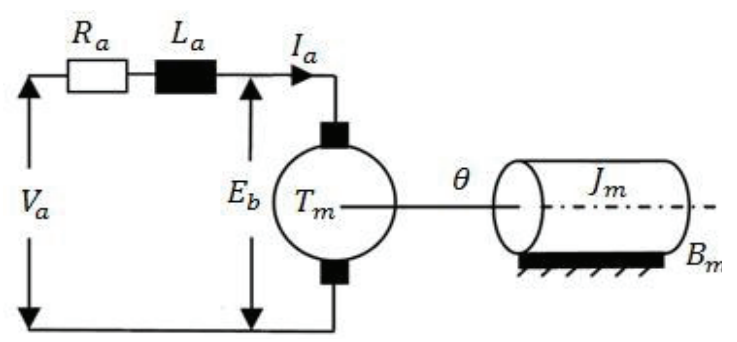

Fig. 1. PMDC motor equivalent circuit.

$$
\begin{aligned}
& T_{m}=\text { motor torque }(\mathrm{Nm}) \\
& w_{m}=\text { angular speed }(\mathrm{rad} / \mathrm{s}) \\
& \theta=\text { angular position of rotor shaft }(\mathrm{rad})
\end{aligned}
$$

\section{Control of PMDC Motor with PI Controller}

In the control of industrial systems, conventional PI controllers are the most common and the most useful ones. In this controller, the proportion (P) and integral (I) operations were combined. The purpose of the control methods is to provide the system with optimal operating performance. For this purpose, proportional gain $(\mathrm{P})$ is an indispensable part of control systems. For; the first and foremost aim of many systems is to provide gain. On using (P) control, the system gain can be easily decreased and increased as if it was set by a button. Thus, it provides to reply of system quickly by making improvements in damping ratio. However, the increase of gain decreases the sensitivity to the parameter changes on the system and leads to an increase in steady state error. In this case, there is a need for an additional structure to eliminate the steady state error. Here integral (I) effect comes into action. When (I) controller is used in a controller structure, the steady state error is reduced or eliminated. However, (I) controller can lead to a negative effect on damping. Also (I) controller increases the degree of the system one degree. Therefore, PI structure is preferred rather than only (I) controller. For, the stability in the structure of proportion effect and the integral effect's advantages of decreasing steady state error were combined in PI control $[5,6]$. In the PI control implementation prepared in this study, the closed cycle Ziegler-Nichols frequency response method was used in the setting of controllers' parameters. The first things to do in these methods are [7, 8]:

1. Making the integral time constant $T_{i}=\infty$ infinite, the effect of integral parameter of controller was eliminated.

2. The proportion coefficient $K p$ value is raised up to $\mathrm{Ku}$ critical value that system response oscillates in the form of sinus.

3. Putting the critical $K u$ gain and the $P u$ values which are the oscillation period composed by this gain into their place in Table 1 in the equations written for PI control, the proportion coefficient and integral time constant $(T i)$ values are obtained.

The output expression of PI type classical controller $u(t)$ and transfer function $C(s)$ are expressed Eqs. (7-8).

$$
u(t)=\left\{\begin{array}{l}
K_{P} * e(t)+K_{I} * \int_{0}^{t} e(t) * d t \\
K_{p} *\left(e(t)+\frac{1}{T_{i}} * \int e(t) * d t\right)
\end{array}\right.
$$


Table 1. The rules of Zigler-Nichols setting method

\begin{tabular}{c|c|c}
\hline Controller & $\mathrm{K}_{\mathrm{p}}$ & $\mathrm{T}_{\mathrm{i}}$ \\
\hline $\mathrm{P}$ & $0.50 * \mathrm{Ku}$ & $\infty$ \\
\hline $\mathrm{PI}$ & $0.45 * \mathrm{Ku}$ & $\mathrm{Pu} / 1.2$ \\
\hline $\mathrm{PID}$ & $0.60 * \mathrm{Ku}$ & $0.5 * \mathrm{Ku}$ \\
\hline
\end{tabular}

$$
C(s)=K_{\mathrm{P}}+\frac{K_{I}}{s}=\frac{K_{P} * s+K_{I}}{s}
$$

PMDC motor's robust speed control with PI controller is designed at Matlab/Simulink program such that Fig. 7. In the linear and nonlinear reference speeds and steady and variable loads, performance comparisons between the fuzzy logic and conventional PI controls were shown separately in graphics in Figs. 9-11-12.

\section{The Control of PMDC Motor with FL}

In recent years, the fuzzy logic controllers have been used quite often in industrial applications. The fuzzy logic approach gives the machines the ability to process the special data of people and to run making use of their experiences and predictions. While providing this ability, instead of numerical expressions, symbolic expressions are used. The fuzzy systems can be used for different purposes such as for modelling, data analysis, estimation and control [9-13]. FL is simply composed of three main parts. These are fuzzification, rule base and defuzzification processes respectively. In Fig. 2, fuzzy system block scheme is shown. In Fig. 3, Mamdani fuzzy interface developed for the fuzzy logic control of the system was showed.

Fuzzification is to be expressed in the form of membership functions of certain information obtained from

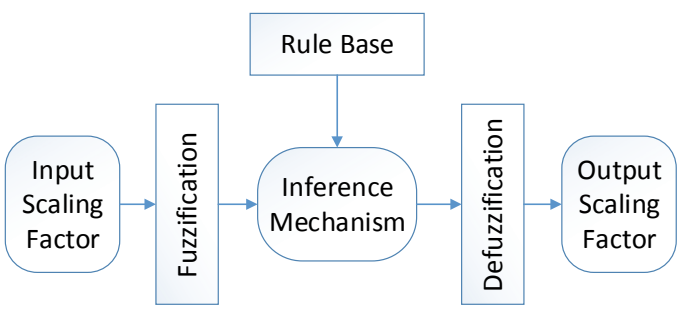

Fig. 2. Architecture of fuzzy logic controller

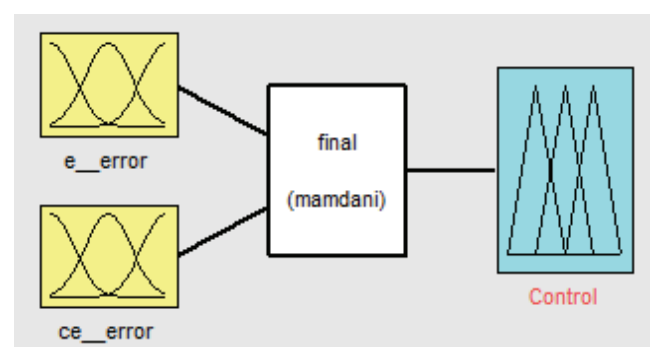

Fig. 3. Mamdani fuzzy inference system developed for fuzzy logic controller the outside world. With this process, certain informations are converted into fuzzy values to be evaluated in the rule base. The rule base is the process of composing proper rules with IF-THEN logic based upon the experience and knowledge about the system. With the evaluation of fuzzy values in the rule base, proper outputs are attained. Because these output values are again fuzzy values, they are necessary that these values are converted into a certain form of information. This procedure where the fuzzy output expression is converted into exact information is called defuzzification [14-18].

In this study, fuzzy logic controller (FL) have been designed for speed control of PMDC motor using Matlab/ Simulink and Fuzzy toolbox. In this controller, as a process variable of motor driver, rotor speed $(w)$, and as a control variable, motor current (ia) were chosen. The system input variables were defined as speed error $(e)$ between reference speed and motor speed, and the change in the speed error (ce). Using 7 linguistic labels for the error $(e(k))$ and error change which are the input signs in the rule base, 9 linguistic labels for output control operation, and 49 rules in total were written. These variable sets were defined as Negative Big $(n b)$, Negative Medium $(n m)$, Negative Small ( $n s)$, Zero ( $z$ ), Positive Small ( $p s)$, Positive Medium $(p m)$ and Positive Big $(p b)$ for inputs, and Negative very Big $(n v b)$ and Positive very Big $(p v b)$ for output in addition to these.

The fuzzy rule base is obtained through the carefully analysis of system behavior. The obtained rules must be written in a way to keep speed error, overshoot, settling time and rising time criteria at minimum values. In this study, rules have been created by analyzing of dynamic signal response given reference speed by PMDC motor that is shown in Fig. 4.

$$
\begin{gathered}
e_{(k)}=\omega_{(r)}-\omega_{(r-1)} \\
c e_{(k)}=e_{(k)}-e_{(k-1)}
\end{gathered}
$$

In the dynamic signal analysis of motor, looking at the

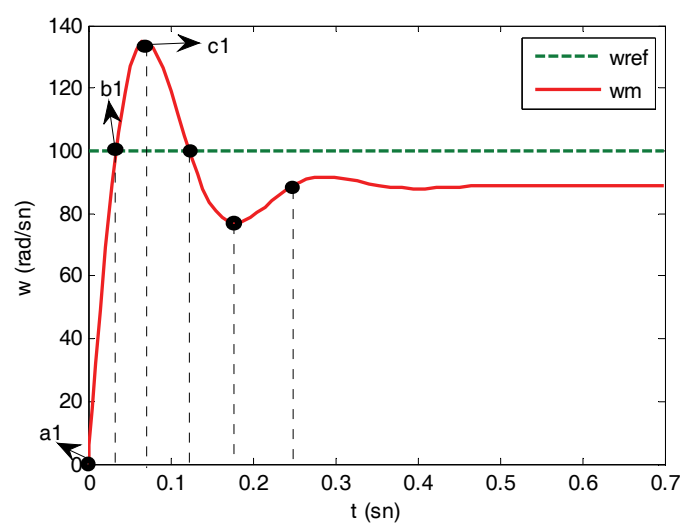

Fig. 4. The dynamic signal analysis of PMDC motor in wref $=100 \mathrm{rad} / \mathrm{s}$ reference speed. 


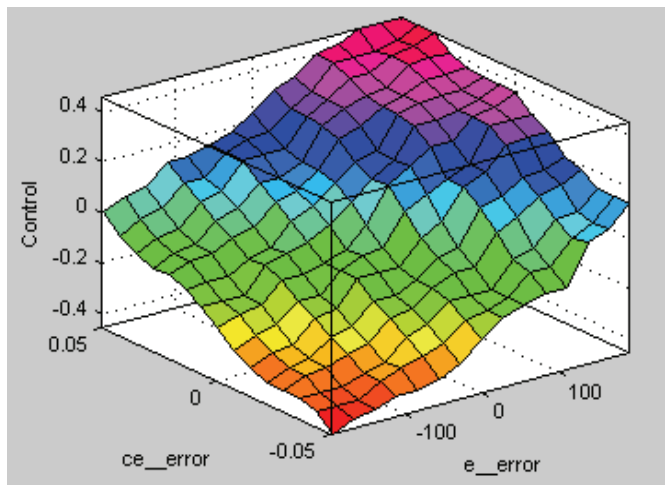

Fig. 5. Surface viewer of fuzzy rules.

Table 2. If - Then rule base of fuzzy logic controller

\begin{tabular}{c|c|c|c|c|c|c|c|c}
\hline Output & \multicolumn{7}{|c}{ Input $\mathrm{e}(\mathrm{t})$} \\
\cline { 2 - 10 } Control & & $\mathrm{nb}$ & $\mathrm{nm}$ & $\mathrm{ns}$ & $\mathrm{Z}$ & $\mathrm{ps}$ & $\mathrm{pm}$ & $\mathrm{pb}$ \\
\hline \multirow{4}{*}{$\begin{array}{c}\text { Input } \\
\text { ce(t) }\end{array}$} & $\mathrm{nb}$ & $\mathrm{nvb}$ & $\mathrm{nb}$ & $\mathrm{nb}$ & $\mathrm{nm}$ & $\mathrm{ns}$ & $\mathrm{ns}$ & $\mathrm{Z}$ \\
\cline { 2 - 10 } & $\mathrm{nm}$ & $\mathrm{nb}$ & $\mathrm{nb}$ & $\mathrm{nm}$ & $\mathrm{ns}$ & $\mathrm{ns}$ & $\mathrm{Z}$ & $\mathrm{ps}$ \\
\cline { 2 - 9 } & $\mathrm{ns}$ & $\mathrm{nb}$ & $\mathrm{nm}$ & $\mathrm{ns}$ & $\mathrm{ns}$ & $\mathrm{Z}$ & $\mathrm{ps}$ & $\mathrm{ps}$ \\
\cline { 2 - 9 } & $\mathrm{Z}$ & $\mathrm{nm}$ & $\mathrm{ns}$ & $\mathrm{ns}$ & $\mathrm{Z}$ & $\mathrm{ps}$ & $\mathrm{ps}$ & $\mathrm{pm}$ \\
\cline { 2 - 9 } & $\mathrm{ps}$ & $\mathrm{ns}$ & $\mathrm{ns}$ & $\mathrm{Z}$ & $\mathrm{pm}$ & $\mathrm{pm}$ & $\mathrm{pb}$ & $\mathrm{pb}$ \\
\cline { 2 - 9 } & $\mathrm{pm}$ & $\mathrm{ns}$ & $\mathrm{Z}$ & $\mathrm{pm}$ & $\mathrm{pm}$ & $\mathrm{pb}$ & $\mathrm{pb}$ & $\mathrm{pvb}$ \\
\cline { 2 - 9 } & $\mathrm{pb}$ & $\mathrm{ps}$ & $\mathrm{ps}$ & $\mathrm{pm}$ & $\mathrm{pb}$ & $\mathrm{pb}$ & $\mathrm{pvb}$ & $\mathrm{pvb}$ \\
\hline
\end{tabular}

signals of error $\left(e_{(k)}\right)$ and error change $\left(c e_{(k)}\right)$ obtained as a result of the calculations made with Eqs. 9 and 10, rules are written according to the situation if it gets away from reference point or not. Error informs us whether it is moved away from the desired reference point or not, and the error change gives the direction of the error. Signal analysis indicates that whether the error and error change exceed the reference point. With the logic of reducing or increasing the current according to reference point (If the error passes the reference point, decrease the current. If the error doesn't reach the reference point, increase the current.), the speed control is carried out. For this purpose, 49 IF-THEN rules written for FL control are shown in Table 2. In the Fig. 5, the control surface of this written rule base is seen.

After the rule base is obtained, it is essential to determine fuzzy inference strategy. In order to realize the fuzzy inference, many techniques such as Max-Dot, MinMax, Tsukamoto and Takagi-Sugeno are used. In this study, Min-Max fuzzy inference method was chosen. The results obtained as a result of the fuzz inference process were made as precise values using one of the defuzzification methods. The defuzzification methods used in the industrial control were given below. Their comparisons with each other to find out the most appropriate one among these methods for this study were made in chapter 5. The comparison result achieved has showed that center of gravity (COG) defuzzification method gives better results. These methods are [19-22];

1. Center of gravity (COG),

2. Bisector of area(BOA),

3. Smallest of maximum (SOM),

4. Mean of maximum (MOM),

5. Largest of maximum (LOM).

In this study, the processes applied in the stage of designing fuzzy logic controller for the robust speed control of PMDC motor are briefly these [23-25]:

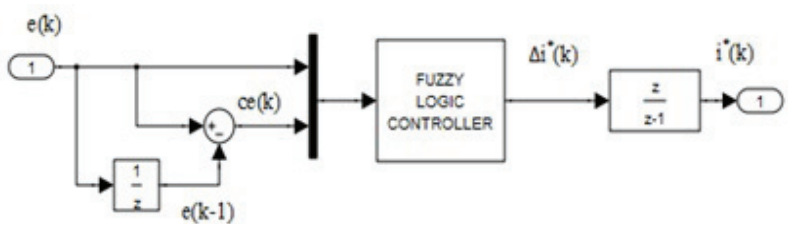

Fig. 6. Fuzzy logic controller structure

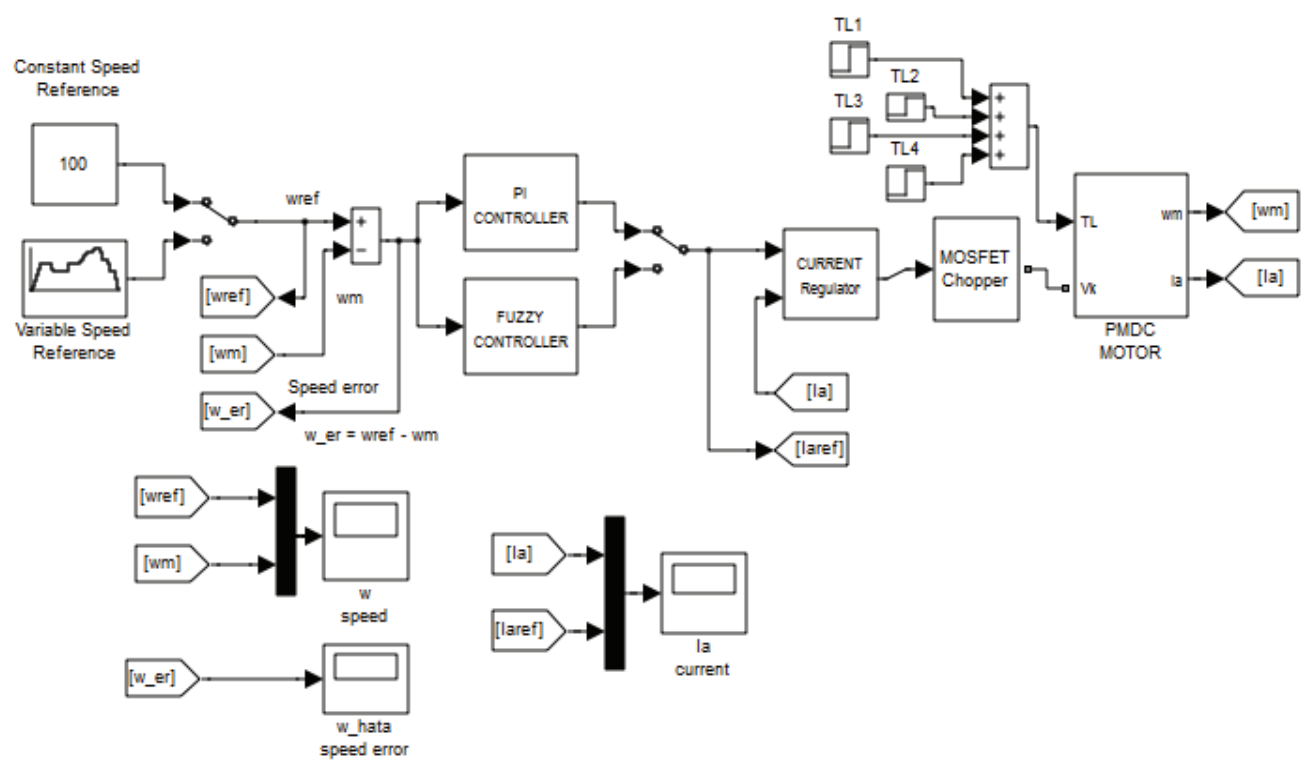

Fig. 7. PMDC motor control designed in Matlab/Simulink program. 
1. Obtaining real speed value of PMDC motor,

2. Calculating speed error $\left(e_{(k)}\right)$ and speed error change $\left(c e_{(k)}\right)$ values,

3. Determining fuzzy sets and membership functions for speed error and speed error change values

4. Determining fuzzy rule base to be applied with the specified fuzzy expressions,

5. The application of $\Delta i^{*}$ and $i^{*}$ values in Eqs. 11 and 12 into the system using weight average method in the defuzzification part.

$$
\begin{gathered}
\Delta i^{*}(k)=\frac{\sum_{i=1}^{n}\left(\Delta i^{*}\right)_{i} \times \mu\left[\left(\Delta i^{*}\right)_{i}\right]}{\sum_{i=1}^{n} \mu\left[\left(\Delta i^{*}\right)_{i}\right]} \\
i^{*}(k)=i^{*}(k-1)+\Delta i^{*}(k)
\end{gathered}
$$

FL controller structure is shown in Fig. 6, and Circuit model designed in Matlab/Simulink program is shown in Fig. 7.

\section{Results and Discussion}

In this section, for robust speed control under different conditions, the results of PMDC motor's simulation realized through using the suggested fuzzy logic and PI control applications were presented. In Table 3, parameters of PMDC motor modelled in Matlab/Simulink program were given.

This study was conducted in three phases. Firstly, the performances of defuzzification methods used in fuzzy logic controller on output signal were discussed. In this context, the different defuzzification methods used in the defuzzification process in the fuzzy logic controller were compared for reference speed (wref) in Fig. 8. The center of gravity method (COG) of these methods has showed a much better performance than other defuzzification to reach the reference speed (wref $=100 \mathrm{~m} / \mathrm{s}$ ) applied to the motor in the range desired criteria. So, PMDC motor with FL controller has reached the desired speed in a very short time and responded in a short time in the sudden load increase by COG method. After this step, COG method will be used as a defuzzification method in the designed fuzzy logic controller for this study.

Table 3. Parameters of PMDC motor

\begin{tabular}{c|c|c|c}
\hline Explanation & Symbol & Unit & Value \\
\hline Shaft Power & $\mathrm{P}$ & $\mathrm{kW}$ & 5 \\
\hline Armature Voltage & $\mathrm{V}_{\mathrm{m}}$ & $\mathrm{V}$ & 240 \\
\hline Armature Resistance & $\mathrm{R}_{\mathrm{m}}$ & $\Omega$ & 0.5 \\
\hline Armature Inductance & $\mathrm{L}_{\mathrm{m}}$ & $\mathrm{H}$ & 0.012 \\
\hline Total İnertia & $\mathrm{J}_{\mathrm{m}}$ & $\mathrm{kgm}^{2}$ & 0.00471 \\
\hline Viscous Friction Coef. & $\mathrm{B}_{\mathrm{m}}$ & $\mathrm{Nms} / \mathrm{rad}$ & 0.002 \\
\hline Torque Constant & $\mathrm{K}_{\mathrm{t}}$ & $\mathrm{Nm} / \mathrm{A}$ & 0.5 \\
\hline Back Emf Constant & $\mathrm{K}_{\mathrm{b}}$ & $\mathrm{Vs} / \mathrm{rad}$ & 0.5 \\
\hline
\end{tabular}

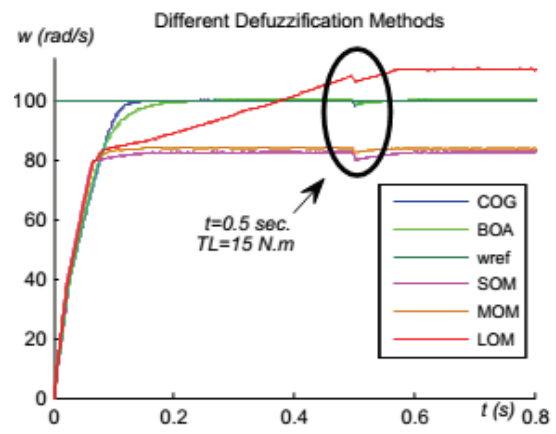

Fig. 8. $w r e f=100 \mathrm{rad} / \mathrm{sec}$ and $T L=15 \mathrm{Nm}$. torque in $0.5 \mathrm{sec}$. with output signal for different defuzzification methods

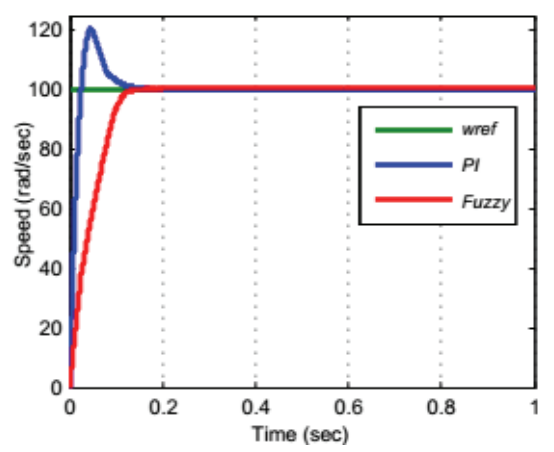

(a)

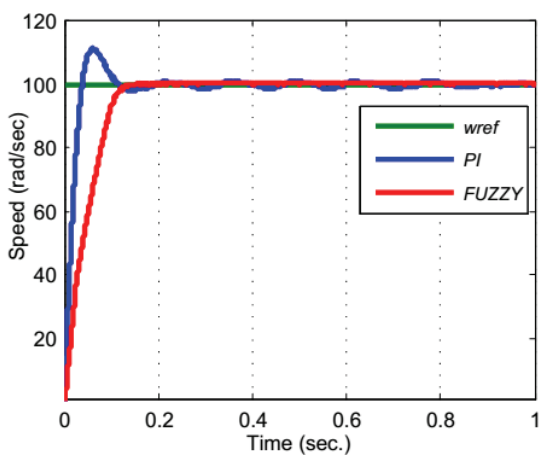

(b)

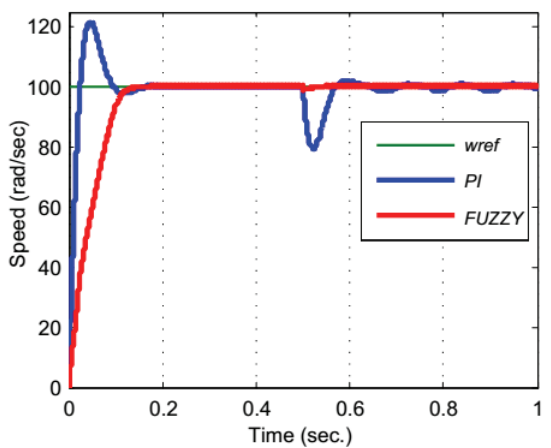

(c)

Fig. 9. PI and Fuzzy logic control for constant in speed (wref $=100 \mathrm{rad} / \mathrm{sec}$ ), (a) under No-load condition. (b) under constant load $\left(T_{L}=15 \mathrm{Nm}\right)$ condition. (c) under $t=0.5 \mathrm{sec}$., suddenly change load $\left(T_{L}=15 \mathrm{Nm}\right)$ condition 
Secondly, performances of fuzzy logic and PI control methods were compared under no-load, load and suddenly changing load for a constant reference speed. In Fig. 9, responses of controllers were analyzed for (a) no-load, (b) load and (c) suddenly changing load for a constant reference speed (wref $=100 \mathrm{~m} / \mathrm{s})$. In PI control at Fig. 9(b), the cause of the oscillation is the integral gain value used if $\mathrm{P}$ proportional value is greater. So the integral value used without the proper damping has led to continuous oscillation in the system. According to the results obtained, fuzzy logic controller with COG defuzzification method has given better results in each case.

Thirdly, responses of FL and PI controllers were evaluated according to nonlinear reference speeds to applied PMDC motor under fixed and variable loads. In the evaluation of vehicles performances, Extra Urban Driving Cycle (EUDC) data of New European Driving Cycle (NEDC) were used as a reference speed. Driving cycle that is the important index to assess the emission levels of car provides the basic data for vehicle design. An often used driving cycle is the New European Driving Cycle (NEDC). The NEDC is supposed to represent the typical use of a car in Europe. This driving cycle contains both city driving with several start-and-stops and motorway driving. It is a good representation of a realistic driving environment. The NEDC consists of four repeated ECE-15 urban driving cycles (UDC) and an Extra- Urban driving cycle (EUDC). The maximum speed of the EUDC cycle is $120 \mathrm{~km} / \mathrm{h}$. Speed versus time curve for EUDC is as shown in Fig. 10. Table 4 shows a summary of the parameters for both the ECE and EUDC cycles [26-28].

In this study, speed/time graph accepted for the behavior

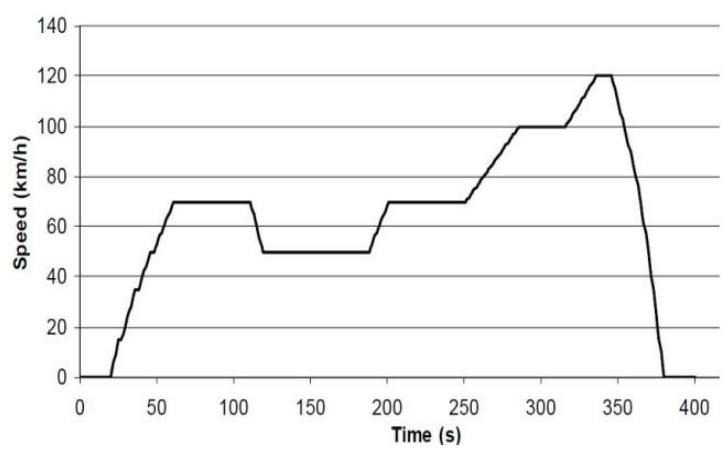

Fig. 10. Speed versus time curve for $\operatorname{EUDC}[26,28]$

Table 4. Parameters of ECE 15 and EUDC [26, 28]

\begin{tabular}{c|c|c}
\hline Characteristics & Unit & ECE 15 \\
\hline Distance & $\mathrm{km}$ & 0.9941 \\
\hline Total time & $\mathrm{s}$ & 195 \\
\hline Idle (standing) time & $\mathrm{s}$ & 57 \\
\hline Average speed & $\mathrm{km} / \mathrm{h}$ & 18.35 \\
\hline Average driving speed & $\mathrm{km} / \mathrm{h}$ & 25.93 \\
\hline Maximum speed & $\mathrm{km} / \mathrm{h}$ & 50 \\
\hline Average acceleration & $\mathrm{m} / \mathrm{s}^{2}$ & 0.599 \\
\hline Maximum acceleration & $\mathrm{m} / \mathrm{s}^{2}$ & 1.042
\end{tabular}

of a vehicle on the extra-urban roads in Europe is taken as reference. Therefore, PI and FL controllers are designed for control of PMDC motor used for driving of an electrical vehicle motor. In Fig. 11-(a, b), responses of FL and PI controllers to speed changing are seen for the EUDC reference speed in no-load condition. In Fig. 12-(a, b), responses of FL and PI controllers to load changing are seen for the EUDC reference speed under variable loads. In Fig. 11-(a), response to reference speed of the PI controller is shown at no load conditions. PI controller reference speed is followed by very well is seen in the acceleration cases of PMDC motor. And but, it is seen not to follow well reference speed in deceleration conditions. In Fig. 12(a), response to reference speed of the PI controller is shown at sudden no load changes. As seen from the Fig, PI controller leads to more deviation from the reference speed in the sudden load increase case of PMDC motor. Then, it can achieve a speed reference. This means that it cannot respond to sudden power and speed changes of electric vehicles in the variable environment-road conditions. When the results were analyzed, fuzzy logic controller versus PI controller provides better desired criteria for PMDC motor control. This means that, travelling by an electrical vehicle driven by fuzzy logic controlled PMDC motor will give us more comfortable, roomy and a safe driving enjoyment.

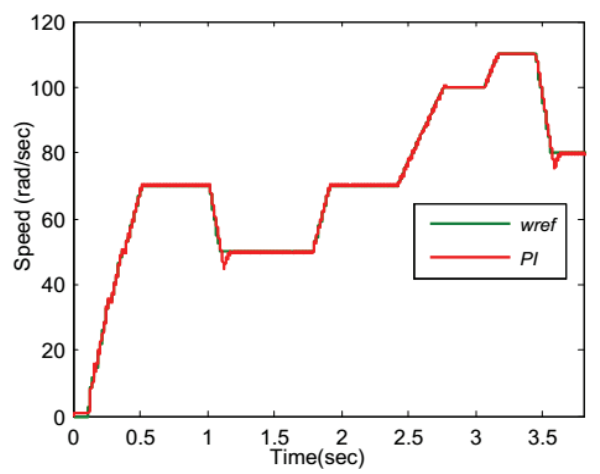

(a)

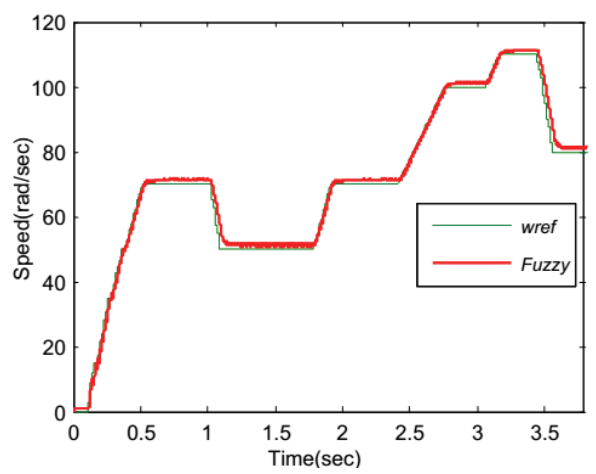

(b)

Fig. 11. (a) PI control for changing in speed under No-load condition. (b) Fuzzy logic control for changing in speed under No-load condition. 


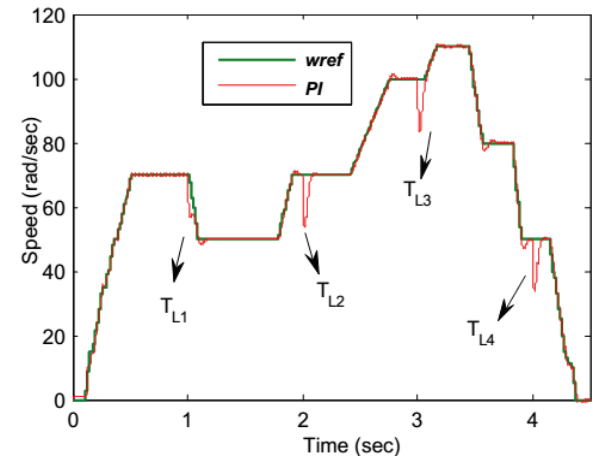

(a)

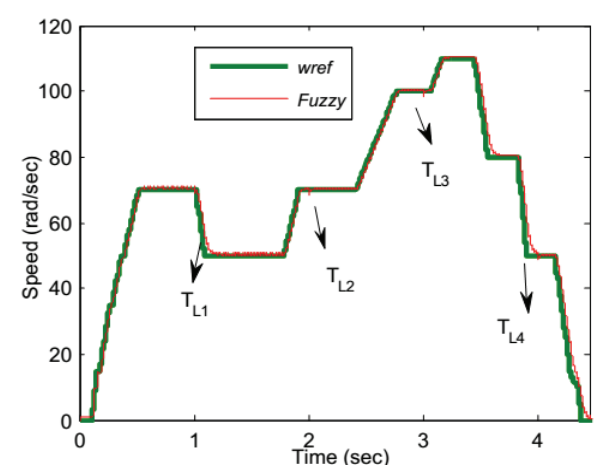

(b)

Fig. 12. (a) PI control for change in speed under changing load condition. (b) Fuzzy logic control for changing in speed under changing load condition $\left(\mathrm{T}_{\mathrm{L} 1}=10\right.$ $\mathrm{Nm}$ in $\mathrm{t} 1=1 \mathrm{~s}, \mathrm{~T}_{\mathrm{L} 2}=10 \mathrm{Nm}$ in $\mathrm{t} 2=2 \mathrm{~s}, \mathrm{~T}_{\mathrm{L} 3}=10 \mathrm{Nm}$ in $\mathrm{t} 3=3 \mathrm{~s}$ and $\mathrm{T}_{\mathrm{L} 4}=10 \mathrm{Nm}$ in $\mathrm{t} 4=4 \mathrm{~s}$ for $\mathrm{T}_{\mathrm{Ltop}}=40 \mathrm{Nm}$.)

\section{Conclusion}

During the control, the control elements have to meet specific performance requirements. The performance of the control system is usually determined by measuring the characteristics of a particular waveform or system response. The desired characteristics in speed control are rise time, settling time, overshoot, and steady-state error that shown in Fig. 2.13.

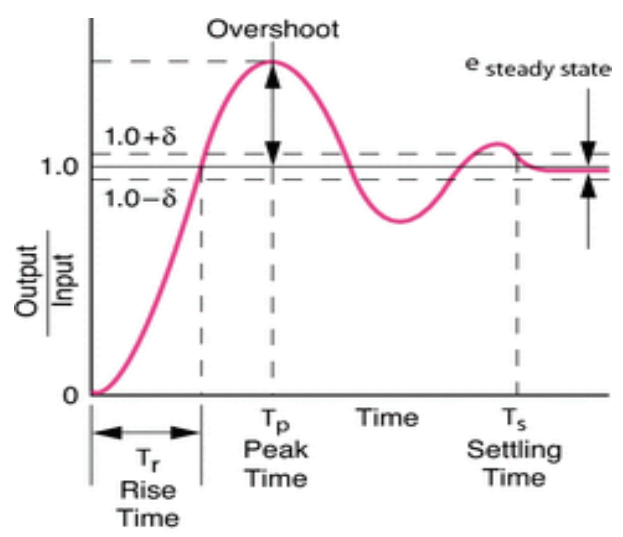

Fig. 13. The waveform characteristics of control element
Rise Time is the amount of time the system takes to go from $10 \%$ to $90 \%$ of the steady-state, or final value.

Percent Overshoot is the amount that the process variable overshoots the final value, expressed as a percentage of the final value. Settling time is the time required for the process variable to settle to within a certain percentage (commonly 5\%) of the final value [29].

Steady-State Error is the final difference between the process variable and set point.

According to simulation results, the desired optimum performance criteria such as less overshoot, $(M p)<10 \%$, no steady state error $(e s s)<1 \%$, minimum settling time $(t s)<2 s$ and minimum rising time $(t r)<1$ s are given in Table 5. According to Table 5, it was seen that the fuzzy logic controller met the desired optimum performance criteria more accurately and robustly compared to the conventional PI control method. Fuzzy logic controller showed very less overshoot according to the PI controller for unloaded, loaded and the suddenly changing load conditions. When analyzed according to the settling time, it is seen that fuzzy logic controller has less settling time according to the PI controller in all circumstances. For example; under variable load, while PI controller has 0.5 second settling time fuzzy controller has 0.046 settling time. In addition, while fuzzy control don't have the steady-state error under the all circumstances PI controller's steadystate error is $1 \%$ in unloaded condition is $2.5 \%$ in loaded condition and is $3.45 \%$ in condition of suddenly changing load. When compared in terms of rise time, it can be said that PI controller is faster than the fuzzy controller. In conclusion, it has been found that the fuzzy logic controller is an effective controller in the steady and variable speedload control applications of PMDC motor (i.e. electrical vehicle).

Table 5. Parameters of control systems PI and Fuzzy Logic Controller

\begin{tabular}{c|c|c|c|c|c}
\hline \multicolumn{2}{c|}{} & $\mathrm{t}_{\mathrm{r}}$ & $\mathrm{e}_{\mathrm{ss}} \%$ & $\mathrm{t}_{\mathrm{s}}$ & $\mathrm{M}_{\mathrm{p}} \%$ \\
\hline \multirow{2}{*}{ No Load } & PI & 0,025 & 1,00 & 0,2120 & 21 \\
\cline { 2 - 6 } & FL & 0,1064 & -- & 0,1170 & -- \\
\hline $\mathrm{T}_{\mathrm{L}}=15 \mathrm{Nm}$ under \\
constant load & PI & 0,045 & 2,50 & 0,9730 & 12 \\
\cline { 2 - 6 } & FL & 0,0859 & -- & 0,1508 & -- \\
\hline $\begin{array}{c}\text { under } \mathrm{t}=0.5 \mathrm{sec} ., \text { suddenly } \\
\text { change load }(\mathrm{TL}=15 \mathrm{Nm})\end{array}$ & PI & 0,0747 & 3,45 & 0,5 & $-21,25$ \\
\cline { 2 - 6 } & FL & 0,02 & -- & 0,0464 & -- \\
\hline
\end{tabular}

\section{References}

[1] I. Eminoğlu, I.H. Altaş, "The effects of the number of rules on the output of a fuzzy logic controller employed to a PMDC motor", Computers \& Electrical Engineering, Vol. 24, pp. 245-261, 1998.

[2] Z. Li, H. Yang, "Speed Control of Brushless DC Motor Using Human-Simulated Intelligent Control", International Conference on Industrial Mechatronics and Automation IEEE, pp. 236-240, 2009.

[3] A. Kapun, M. Čurkovič, A. Hace, K. Jezernik, 
"Identifying dynamic model parameters of a BLDC motor", Simulation Modelling Practice and Theory, Vol. 16(9), pp. 1254-1265, 2008.

[4] T.V. Mahendiran, P. Thangam, K. Thanushkodi, "A Comparative Study on Non Linear Drive Control for Separately Excited DC Motor Using Fuzzy Logic Controller Fuzzy PI Controller and PSO Tuned Fuzzy PI Controller", International Journal of Research and Reviews in Electrical and Computer Engineering, Vol. 1(1), pp. 32-38, 2011.

[5] R. Malhotra, T. Kaur, G.S. Deol, "DC motor control using Fuzzy Logic Controller", International Journal of Advanced Engineering Sciences and Technologies, Vol. 8(2), pp. 291-296, 2011.

[6] K. J. Aström, T. Hagglund, "The future of PID control", Control Engineering Practice, Vol. 9(11), pp. 1163-1175, 2011.

[7] M. Dogan, M. Dursun, "Application of Speed control of permanent magnet synchronous machine PID and Fuzzy Logic controller", Energy Education Science And Technology Part A, Vol. 28(2), pp.925-930, 2012.

[8] A. Karakaya, E. Karakaş, "Performance Analysis of PM Synchronous Motors using Fuzzy Logic and Self Tuning Fuzzy PI Speed Controls", The Arabian Journal for Science and Engineering, Vol. 33(1B), pp. 153-177, 2008.

[9] F. Y1kan, "Investigating and Developing Robust PID Controller Design Techniques", Msc.Thesis, Inonu University, Turkey, 2005.

[10] Ö. Akyazı, H. Zenk, A.S. Akpınar, "Permanent Magnet DC Motor Speed Control Using Different Fuzzy Membership Functions", 6th International Advanced Technologies Symposium, Elazı̆̆, Turkey, pp. 163$168,2011$.

[11] M. Namazov, O. Basturk, "DC motor position control using fuzzy proportional-derivate controllers with different defuzzification methods", Turkish Journal of Fuzzy Systems, Vol. 1(1), pp. 36-54, 2010.

[12] S.R. Khuntia, K.B. Mohanty, S. Panda, C. Ardil, "A Comparative Study of P-I, I-P, Fuzzy and NeuroFuzzy Controllers for Speed Control of DC Motor Drive", International Journal of Electrical and Computer Engineering, Vol. 5(5), pp. 287-291, 2010.

[13] I. Eker, Y. Torun, "Fuzzy logic control to be conventional method", Energy Conversion and Management, Vol. 47, pp. 377-394, 2006.

[14] S. Yuvarajan, A. Khoei, K. Hadidi, "Fuzzy logic DC motor controller with improved performance", Industry Applications Conference IEEE, Vol. 3, pp. 1652-1656,1998.

[15] L. Mathew, V. K. Pandey, "Design and development of fuzzy logic controller to control the speed of permanent magnet synchronous motor", Journal of Electrical and Electronics Engineering Research, Vol. 3(3), pp. 52-61, 2011.

[16] R. Kandiban, R. Arulmozhiyal, "Design Adaptive
Fuzzy PID Controller for speed control of BLDC motor", International Journal of Soft Computing and Engineering, Vol. 2(1), pp. 386-391, 2012.

[17] T.C. Siong, I. Baharuddin, S.F. Siraj, F.M. Mohd, "Fuzzy Logic Controller for BLDC Permanent Magnet Motor Drives", International Journal of Electrical \& Computer Sciences, Vol. 11(2), pp. 1318, 2011.

[18] K. H. Chua, W.P. Hew, C.P. Ooi, C.Y. Foo, K. S. Lai, "A Comparative Analysis of PI, Fuzzy Logic and ANFIS Speed Control of Permanent Magnet Synchronous Motor", Int. Journal of Electrical, Electronic Engineering and Technology, Vol. 1(10), pp. 10-22, 2011.

[19] M.V. Ramesh, J. Amarnath, S. Kamakshaiah, G.S. Rao, "Speed Control of Brushless DC motor by using Fuzzy Logic PI controller", ARPN Journal of Engineering and Applied Sciences, Vol. 6(9), pp. 55-62, 2011.

[20] E. Natsheh, K.A. Buragga, "Comparison between Conventional and Fuzzy Logic PID Controllers for Controlling DC Motors", International Journal of Computer Science, Vol. 7(5), pp. 128-134, 2010.

[21] J. Choi, C.W. Park, S. Rhyu, H. Sung, "Development and Control of BLDC Motor Using Fuzzy Models", Robotics, Automation and Mechatronics IEEE, pp. 1180-1185, 2004.

[22] Y. Guo, H. Long, "Self-organizing fuzzy sliding mode controller for the position control of a permanent magnet synchronous motor drive", Ain Shams Engineering Journal, Vol. 2, pp. 109-118, 2011.

[23] P. Ananthababu, B.A. Reddy, "Control of PMDC motor using fuzzy PI controller", Control, Automation, Communication and Energy Conservation, pp. 1-4, 2009.

[24] I. Yabanova, M. Yumurtaci, A. Kecebas, “Development of PID and Fuzzy Logic controller simulator for control systems education", Energy Education Science and Technology Part B, Vol. 4(1), pp. 67-76, 2012.

[25] R. Arulmozhiyal, R. Kandiban, "Design of Fuzzy PID controller for Brushless DC motor", Computer Communication and Informatics, pp. 1-7, 2012.

[26] T.J. Barlow, S. Latham, I.S. McCrae, P.G. Boulter, "A Reference Book of Driving Cycles for Use in the Measurement of Road Vehicle Emissions", PPR354, pp. 3-25, 2009.

[27] E. Schaltz, "Electrical Vehicle Design and Modeling, Electric Vehicles - Modelling and Simulations", S. Soylu (Ed.), InTech, Aalborg University, pp. 1-24, 2011.

[28] V. Wynen, F.S. Boureima, J. Matheys, P. Van den Bossche, J. Van Mierlo, "Developing applicable driving cycle for retrofitted Plug-In Hybrid Electric Vehicles (PHEVs): environmental impact assess-ment", World Electric Vehicle Journal, Vol. 3, pp. 1-7, 2009.

[29] Access date: http://www.ni.com/white-paper/3782/en/ 


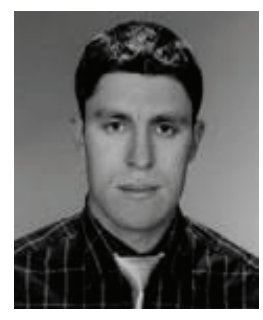

Murat Tuna He received B.S and M.S. degrees in electrical education from Kocaeli University, Turkey, in 2004 and 2009 respectively. His research interests are electric vehicles, fuzzy logic, neural networks, and automatic control. He has been working as a Lecturer at Kirklareli University since 2009. He is currently pursuing the Ph.D. degree at Karabuk University.

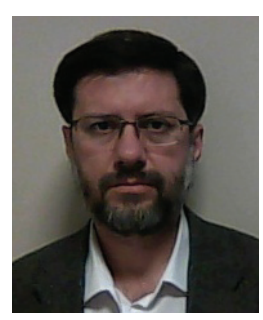

Can Bülent Fidan He received the BSc. and MSc. Degree in Electronics and Communications Engineering in 1988 and 1991, respectively, and the Ph.D. degree in Elecrical Engineering in 2001, all from the Yildiz Technical University, Istanbul, Turkey. He is currently Assistant Professor of Mechatronics Engineering at the Karabuk University, Karabuk, Turkey. His main research interest are signal processing and intelligent control applications, neural networks.

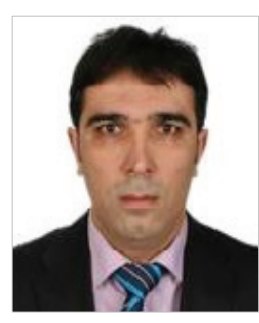

Süreyya Kocabey He received the B.S., M.S. and Ph.D. degrees in electrical education from Marmara University, Turkey, in 1995, 1999 and 2008 respectively. He has been working as an Assistant Professor at Kirklareli University since 2009. His research areas are indoor lighting, energy saving, energy management in buildings.

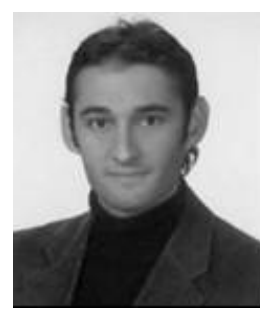

Sertaç Görgülü He received the B.S., M.S. and Ph.D. degrees in electrical education from Marmara University, Turkey, in 2001, 2004 and 2011 respectively. He has been working as an Assistant Professor at Mehmet Akif University since 2013. His research areas are indoor lighting, energy management in buildings, fuzzy logic and and automatic control. 